\title{
A possible role of plasma glutathione in glucose-mediated insulin secretion: in vitro and in vivo studies in rats
}

\author{
H.P.T.Ammon ${ }^{1}$, S.Klumpp ${ }^{1}$, A. Fu $\beta^{1}$, E.J.Verspohl ${ }^{1}$, H.Jaeschke ${ }^{2}$, A. Wendel ${ }^{2}$ and P. Müller ${ }^{2}$ \\ ${ }^{1}$ Institute of Pharmaceutical Sciences, Department of Pharmacology, and \\ ${ }^{2}$ Institute of Physiological Chemistry, Medical Department, University of Tübingen, Tübingen, FRG
}

\begin{abstract}
Summary. In isolated rat pancreatic islets exogenous glutathione which is not able to penetrate into cells, augmented glucose $(11.1 \mathrm{mmol} / \mathrm{l})$-mediated insulin release. In the presence of a non-stimulatory glucose concentration $(2.8 \mathrm{mmol} / \mathrm{l}) \mathrm{glu}-$ tathione had no effect. The half-maximal synergistic action of glutathione on insulin secretion was observed at approximately $8.0 \mu \mathrm{mol} / 1$. This concentration of glutathione is similar to that found in the plasma of non-fasted anaesthetised rats
\end{abstract}

$(6.5 \mu \mathrm{mol} / 1)$. Oral ingestion of glucose increased the arterial plasma glutathione in rats. Our data provide for the first time indirect evidence for a modulating effect of plasma glutathione in postprandial glucose-mediated insulin secretion which appears to be located at the extracellular site of islet cells.

Key words: Plasma glutathione, insulin secretion.
In vitro stimulation of insulin release by glucose has been suggested to depend on the intracellular redox state of islet thiols. This view is based on observations that the insulin secretory action of glucose can be blocked by membrane penetrating thiol oxidants [1-4], and that both islet reduced glutathione (GSH) and the reduced glutathione/oxidized glutathione (GSH/ GSSG) ratio are increased during an elevation of the glucose concentration $[4,5]$. GSH has been reported to potentiate glucose-induced insulin secretion in vitro [6, 7]. GSH is a physiological constituent of blood plasma; its blood concentration is far less than its intracellular concentration. In the plasma of anaesthetised rats it was found to be approximately $10-15 \mu \mathrm{mol} / 1$ [8]. Whereas intracellular glutathione plays an important role in the activity of many enzymes [9], to our knowledge there is no evidence yet as to whether plasma GSH possesses direct physiological functions as well. In order to obtain evidence whether or not plasma GSH might play a physiological role in glucose-mediated insulin secretion, we studied first whether the dose-response curve of the GSH action on insulin release in vitro is in the range of plasma GSH levels, second whether plasma GSH is increased in vivo in response to oral glucose administration, and third whether GSH added in vitro is able to penetrate into islet cells.

\section{Materials and methods}

The following were purchased: Collagenase (Worthington Biochemical Corp., Freehold, NJ, USA), D-glucose, N-acetylcysteine (Serva Feinbiochemica, Heidelberg, FRG), bovine serum albumin (Behring- werke, Marburg, FRG), reduced glutathione (GSH 98\%, GSSG $<1,5 \%$, iron $10 \mathrm{ppm}$, specified and supplied by Boehringer, Mannheim, FRG), oxidized glutathione (GSSG), glutathione reductase, glyoxalase I, NADPH, 5,5-dithiobis-(-nitrobenzoic acid) (DTNB) (Boehringer), metaphosphoric acid (Fluka, Buchs, Switzerland), heparin-Na (Medac, Hamburg, FRG), N-morpholinopropanesulfonic acid (MOPS) (Sigma, St. Louis, Mo., USA), methylglyoxale (EGA Chemie, Steinheim, FRG), rat insulin (Novo Lab., Copenhagen, Denmark), insulin radioimmunoassay kit (INSIK-1, CISSORIN, Italy, supplied by Isotopendienst West, Dreieich, FRG), [glycine-2- ${ }^{3} \mathrm{H}$ ]-glutathione $(892 \mathrm{Ci} / \mathrm{mol}$ ) (New England Nuclear, Boston, Mass., USA), $\left[{ }^{3} \mathrm{H}\right]$ sucrose $(9800 \mathrm{Ci} / \mathrm{mol}$ ) (Amersham Buchler, Braunschweig, FRG) and silicone oil (Versilub F 50) (Klöckner, Duisburg, FRG). All other chemicals and reagents of analytic grade were obtained from E. Merck (Darmstadt, FRG) and Boehringer Mannheim.

\section{Animals}

Equal numbers of male and female Wistar rats from a local strain, weighing $200-300 \mathrm{~g}$, were used. They were kept on a standard pellet diet (Altromin, Lage, FRG) and were given water ad libitum. Room temperature was $22^{\circ} \mathrm{C}$, humidity was $45 \%$ and there was a $12 \mathrm{~h}$ light/dark cycle.

\section{In vitro studies}

Isolation and incubation of islets. Rats were anaesthetised with ether, and the pancreatic islets were prepared and harvested by the collagenase method of Lacy and Kostianovksy [10]

Studies on insulin release. Islets were initially preincubated for $30 \mathrm{~min}$ in the medium described above, containing, in addition, $2.8 \mathrm{mmol} / 1$ glucose while being gassed with carbogen. After preincubation, islets were washed three times with ice-cold Hanks' solution. For a second 
preincubation, batches of 5 islets were placed in plastic tubes fitted with a nylon net at the bottom $[11,12]$. These tubes were then transferred into reaction tubes containing the incubation medium which consisted of $1 \mathrm{ml}$ of Krebs-Ringer bicarbonate (KRB) buffer together with $2 \%$ bovine serum albumin and 2.8 or $11.1 \mathrm{mmol} / \mathrm{l}$ glucose. Incubation of the islets was carried out at $37^{\circ} \mathrm{C}$ for 30 min under continuous shaking ( 100 strokes/min) and gassing with carbogen. This second preincubation was introduced since it is well known from previous experiments that the effect of exogenous thiols is obvious only after a lag time [11]; this includes the process of getting the islets adapted from $4^{\circ} \mathrm{C}$ to the physiological temperature.

Therefore, for the main incubation (the measurement of insulin release) the nylon net tubes with the islets were transferred into a second set of reaction tubes now containing $1 \mathrm{ml}$ basal medium with 2.8 or $11.1 \mathrm{mmol} / \mathrm{l}$ glucose with varying concentrations of GSH. GSH containing media were prepared at $0^{\circ} \mathrm{C}$ immediately before incubation. After incubation for $10 \mathrm{~min}$ aliquots of medium were taken for insulin assay. Due to rapid oxidation of GSH in the incubation medium (KRB) under gassing with carbogen [11] we selected with respect to the GSH experiments a time period of as little as $10 \mathrm{~min}$.

Studies on uptake of exogenous GSH. Uptake of [ $\left.{ }^{3} \mathrm{H}\right] \mathrm{GSH}$ was studied in comparison with the uptake of $\left[{ }^{3} \mathrm{H}\right]$ sucrose used as an impermeable reference compound. The incubations were carried out in prewarmed $\left(37^{\circ} \mathrm{C}\right)$ polypropylene tubes $(0.5 \mathrm{ml})$ containing $150 \mu \mathrm{l}$ silicone oil layered on $25 \mu \mathrm{l}$ of $3 \mathrm{~mol} / 1$ potassium hydroxide $(\mathrm{KOH})$. At time 0 medium containing $\left[{ }^{3} \mathrm{H}\right]$ GSH or both labelled and unlabelled sucrose was added to the tubes; the medium consisted of either $0.1 \mathrm{mmol} / 1$ GSH with $0.13 \mu \mathrm{Ci} / 200 \mu \mathrm{l}\left[{ }^{3} \mathrm{H}\right] \mathrm{GSH}$ or $0.1 \mathrm{mmol} / 1$ sucrose with $1.96 \mu \mathrm{Ci} / 200 \mu \mathrm{l}\left[{ }^{3} \mathrm{H}\right]$ sucrose. After $10 \mathrm{~min}$ of incubation the islets were separated from the radioactive medium by centrifugation ( $10 \mathrm{~s}$ at $15000 \mathrm{rev} / \mathrm{min}$ ) through the water impermeable silicone oil into $\mathrm{KOH}$. The tip of the tube was cut and its radioactivity counted in a scintillation counter.

Perfusation of isolated livers. The liver is the most important organ for the release of GSH into the blood plasma. In order to obtain information as to whether glucose itself or released insulin might be responsible for the elevation of plasma GSH, isolated rat livers were perfused to study a possible effect of glucose and insulin on sinusoidal GSH efflux. The liver preparation and perfusion was as previously described $[13,14]$. The perfusate was circulated with a peristaltic pump at a constant flow rate of $>3 \mathrm{ml} \cdot \mathrm{min}^{-1} \cdot \mathrm{g}^{-1}$ liver wet weight. The bile duct was cannulated by polyethylene tubing $(0.4 \mathrm{~mm}$ inner/diameter). After a preperfusion period of $40 \mathrm{~min}$, starting with the cannulation of the portal vein, infusion of different solutions containing glucose $(5.6$ and $16.7 \mathrm{mmol} / 1)$, insulin $(200 \mu \mathrm{U} / \mathrm{ml})$ with and without glucose into the portal vein were performed. During the infusion periods a volume of $0.8 \mathrm{ml} / \mathrm{min}$ (containing test substances) was added to the perfusate $(30 \mathrm{ml} / \mathrm{min})$. The viability of the isolated liver preparations which has been described and discussed in detail $(13,14)$ was checked by determination of the lactate/pyruvate ratio $(<6)$ and the lactate dehydrogenase (LDH) release into the effluent perfusate $\left(<10 \mathrm{mU} \cdot \min ^{-1} \cdot \mathrm{g}^{-1}\right.$ liver wet weight) and the slow linear decrease of the bile flow $\left(1.26 \pm 0.08 \mu \mathrm{l} \cdot \mathrm{min}^{-1} \cdot \mathrm{g}^{-1}\right.$ liver wet weight at $30 \mathrm{~min}$; $0.86 \pm 0.10$ at $120 \mathrm{~min})$

\section{In vivo studies}

In the in vivo studies the effect of an oral glucose load on plasma glucose, GSH and GSSG were tested in rats. The non-fasted animals were anaesthetised at 12.00 hours by an i.p. injection of $50 \mathrm{mg} / \mathrm{kg}$ pentobarbitone-Na. After tracheotomy for artificial respiration, a gastric tube was inserted, and polyethylene catheters were introduced into both a jugular vein for substitution of blood volume with isotonic $\mathrm{NaCl}$ and a carotid artery for taking blood samples. After attaching the respiration pump, the rats were heparinized $(500 \mathrm{U} / 100 \mathrm{~g}$ body weight).
Oral glucose $1 \mathrm{~g}$ glucose $/ \mathrm{kg}$ body weight in $2 \mathrm{ml}$ of distilled water or water alone (controls) was administered orally and blood samples were taken after 10,25, and $40 \mathrm{~min}$. The possible efflux of GSH from erythrocytes was indirectly checked by assaying plasma potassium levels with a flame photometer which showed that no GSH efflux was occurring.

Assay of glucose, GSH and GSSG. Blood was collected in cooled polyethylene tubes and immediately centrifuged at $3^{\circ} \mathrm{C}, 10000 \mathrm{~g}$, for $2 \mathrm{~min}$. Protein was precipitated by adding $120 \mu \mathrm{l}$ plasma to $30 \mu \mathrm{l}$ ice cold 10\% (weight/weight) metaphosphoric acid. The sample was centrifuged again for $3 \frac{1}{2} \mathrm{~min}$, and $70 \mu 1$ of the acid soluble supernatant was diluted with $280 \mu \mathrm{l} 3 \%$ (weight/weight) metaphosphoric acid. Plasma glucose was measured immediately by the glucose oxidase method using a Beckman Glucose Analyzer 2 (Beckman, Palo Alto, Calif., USA). The samples for glutathione determination were then frozen in liquid nitrogen. Immediately before the analysis $40 \mu \mathrm{l}$ of this solution were neutralized with an equivalent volume of $0.3 \mathrm{~mol} / 1$ MOPS $/ 0.5 \mathrm{~mol} / 1 \mathrm{KOH}$. For measuring GSSG $60 \mu \mathrm{l}$ were used. All determinations were done in triplicate.

Total glutathione was measured by the kinetic assay using the glutathione reductase reaction with 5,5-dithiobis-(-nitrobenzoic acid) (DTNB) essentially as described by Brehe and Burch [15]. GSSG was measured by transforming GSH to S-lactoyl-glutathione with methylglyoxal, catalyzed by glyoxalase 1, according to Heinle [16] followed by the kinetic determination of total glutathione as described above. GSH was calculated as total glutathione minus 2 GSSG. Calibrations were carried out by the principles of external standards using a GSH/GSSG ratio of $4: 1$.

Radioimmunoassay of insulin. Insulin released into the incubation medium was assayed radioimmunologically using the double antibody technique of Soeldner and Slone [17]. Since GSH may react with the disulfide bridges of insulin and, therefore, might cause an underestimation of the amount of insulin released, the effect of various concentrations of GSH used in this study on calibration curves of insulin radioimmunoassay was investigated. The results have been previously reported $[7,11]$.

\section{Statistical analysis}

The student's $t$-test and $t$-test for paired data were used for statistical evaluation of the results. For multiple comparisons of means two-way analysis of variance (F-test) was performed followed by Student's $t$ test. Values are given as mean $\pm \mathrm{SEM} ; n=$ number of experiments from separate preparations of islets and separate in vivo experiments.

\section{Results}

\section{Isolated islets}

Figure 1 shows the effect of GSH on insulin secretion in the presence of 2.8 and $11.1 \mathrm{mmol} / 1$ glucose. Whereas GSH had no effect at the substimulatory glucose level $(2.8 \mathrm{mmol} / \mathrm{l})$, GSH augmented glucose $(11.1 \mathrm{mmol} / \mathrm{l})$ mediated insulin release; its half maximal effect was detectable with as little as $10 \mu \mathrm{mol} / 1$.

Uptake of radioactively labelled GSH by rat pancreatic islets was investigated. No significant increase in radioactivity could be observed when uptake of GSH was compared with experiments using $\left[{ }^{3} \mathrm{H}\right]$ sucrose (Fig.2): Uptake of radioactivity after $10 \mathrm{~min}$ of incubation time was $1.765 \pm 0.140$ pmol $\left[{ }^{3} \mathrm{H}\right] \mathrm{GSH}$ and 
$1.448 \pm 0.156 \mathrm{pmol}\left[{ }^{3} \mathrm{H}\right]$ sucrose per 10 islets $(n=5)$. Even the real uptake of GSH (corrected for sucrose "uptake") was only $1 \%$ of the GSH content in islets.

\section{Perfused liver}

In experiments employing isolated perfused liver the basal sinusoidal efflux of GSH+2 GSSG (15.9 $\pm 1.0 \mathrm{nmol} \mathrm{GSH} \cdot \mathrm{min}^{-1} \cdot \mathrm{g}^{-1}$ liver weight; $n=3$ ) was not increased by the addition of 5.6 and $16.7 \mathrm{mmol} / \mathrm{l}$ glucose. Even a slight decrease was observed (14.1 $\pm 0.2 \mathrm{nmol} \mathrm{GSH} \cdot \mathrm{min}^{-1} \cdot \mathrm{g}^{-1}$ liver weight, $n=3$, with $5.6 \mathrm{mmol} / 1$ glucose and $13.9 \pm 1.5 \mathrm{nmol} \mathrm{GSH} \cdot \mathrm{min}^{-1}$ $\cdot \mathrm{g}^{-1}$ liver weight, $n=3$, with $16.7 \mathrm{mmol} / 1$ glucose). However, such a decrease could also be detected when $8.35 \mathrm{mmol} / 1 \mathrm{NaCl}$ had been added to the medium $\left(14.3 \pm 1.8 \mathrm{nmol} \mathrm{GSH} \cdot \mathrm{min}^{-1} \cdot \mathrm{g}^{-1}\right.$ liver weight, $\left.n=3\right)$. Simultaneous determination of LDH did not show any significant change during the addition of glucose and/or $\mathrm{NaCl}$ to the perfusion medium, indicating no disturbance of membrane permeability of liver cells.

Infusion of rat insulin $(200 \mu \mathrm{U} / \mathrm{ml})$ for $10 \mathrm{~min}$ with and without simultaneous infusion of glucose $(16.7 \mathrm{mmol} / 1)$ did not affect the basal sinusoidal GSH efflux from the liver.

\section{In vivo studies}

Oral glucose load in rats. In Table 1 the effect of oral glucose on total glutathione (expressed as GSH +2 GSSG), GSH, GSSG and glucose of rat arterial plasma is shown. Twenty-five and $40 \mathrm{~min}$ after glucose administration there was a significant $(p<0.02)$ increase in GSH +2 GSSG, GSH and GSSG, whereas the GSH/GSSG ratio was not changed. Plasma glucose was significantly elevated after 10,25 and $40 \mathrm{~min}$ $(p<0.01)$.

Table 1. Effect of intragastric glucose $(1 \mathrm{~g} / \mathrm{kg})$ administration on plasma reduced glutathione +2 oxidized glutathione $(\mathrm{GSH}+$ 2 GSSG), reduced glutathione (GSH), oxidized glutathione (GSSG) and glucose of rats

\begin{tabular}{lcccc}
\hline \multicolumn{5}{c}{ Time (min) } \\
\cline { 2 - 5 } & 0 & 10 & 25 & 40 \\
\hline GSH+2 GSSG & 8.45 & $9.55^{\mathrm{b}}$ & $11.58^{\mathrm{b}}$ & $12.42^{\mathrm{b}}$ \\
$(\mu \mathrm{mol} / \mathrm{l})$ & \pm 0.75 & \pm 0.71 & \pm 0.97 & \pm 1.16 \\
GSH $(\mu \mathrm{mol} / \mathrm{l})$ & 6.47 & $7.32^{\mathrm{b}}$ & $8.91^{\mathrm{b}}$ & $9.52^{\mathrm{b}}$ \\
& \pm 0.51 & \pm 0.50 & \pm 0.80 & \pm 0.90 \\
GSSG $(\mu \mathrm{mol} / 1)$ & 1.02 & 1.11 & $1.33^{\mathrm{a}}$ & $1.45^{\mathrm{a}}$ \\
& \pm 0.12 & \pm 0.11 & \pm 0.13 & \pm 0.16 \\
GSH/GSSG & 6.34 & 6.48 & 6.70 & 6.56 \\
Glucose & 8.7 & $11.9^{\mathrm{c}}$ & $12.5^{\mathrm{c}}$ & $11.2^{\mathrm{b}}$ \\
(mmol/l) & \pm 0.17 & \pm 0.55 & \pm 0.80 & \pm 0.79 \\
\hline
\end{tabular}

$t$-test for paired data. Mean \pm SEM, $n=8$. ${ }^{\mathrm{a}} p<0.02 ;{ }^{\mathrm{b}} p<0.01$; ${ }^{c} p<0.001$

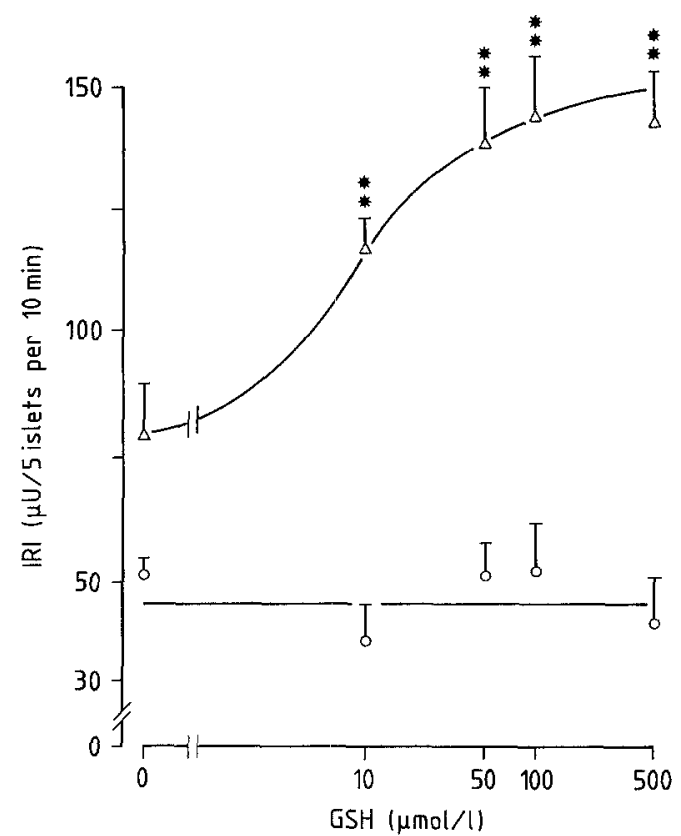

Fig. 1. Effect of reduced glutathione (GSH) on insulin release (IRI) from rat pancreatic islets. Five islets were incubated at $2.8(O)$ or 11.1 $(\triangle) \mathrm{mmol} / 1$ glucose with and without GSH for $10 \mathrm{~min}$. Means \pm SEM of six independent experiments; $t$-test; ${ }^{*} p<0.01$

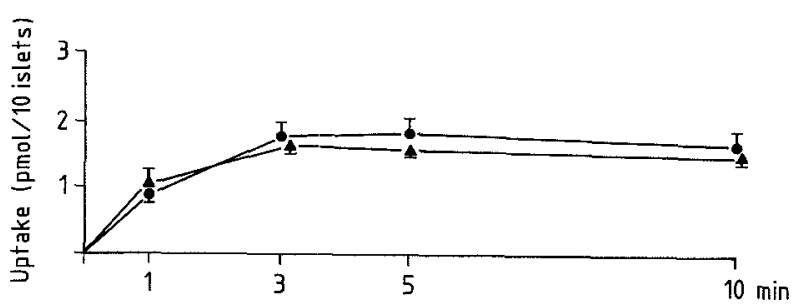

Fig. 2. Time course of $\left[{ }^{3} \mathrm{H}\right] \mathrm{GSH}(\boldsymbol{O})$ and $\left[{ }^{3} \mathrm{H}\right]$ sucrose $(\boldsymbol{\Delta})$ uptake by rat pancreatic islets. Ten islets were incubated for $10 \mathrm{~min}$ at $2.8 \mathrm{mmol} / 1$ glucose with $0.1 \mathrm{mmol} / 1\left[{ }^{3} \mathrm{H}\right] \mathrm{GSH}$ or $\left[{ }^{3} \mathrm{H}\right]$ sucrose. Means \pm SEM of six independent experiments

In control experiments (no oral glucose load) anaesthesia and/or intragastric water ingestion did not significantly change any of the above mentioned parameters at 0 and $40 \mathrm{~min}: \mathrm{GSH}+2$ GSSG $8.73 \pm 0.34$ and $8.50 \pm$ $0.33 \mu \mathrm{mol} / \mathrm{l}$; GSH $5.98 \pm 0.32$ and $5.76 \pm 0.12 \mu \mathrm{mol} / 1$; GSSG $1.38 \pm 0.14$ and $1.37 \pm 0.15 \mu \mathrm{mol} / 1 ; \mathrm{GSH} / \mathrm{GSSG}$ 4.33 and 4.20 ; glucose $8.7 \pm 0.12$ and $8.1 \pm 0.38 \mathrm{mmol} / \mathrm{l})$.

\section{Discussion}

Our data clearly show that exogenous GSH potentiated glucose-induced insulin secretion from rat pancreatic islets in a dose-related manner. The data of Figure 1 also show that GSH does not initiate but rather modulates the insulin secretory action of glucose since it exhibited no effect on insulin secretion in the presence of non-stimulatory glucose $(2.8 \mathrm{mmol} / 1)$. Additionally, from recent studies it was clear that GSH did not affect insulin release at 0 and $5.6 \mathrm{mmol} / 1$ glucose [11]. How- 
ever, the potentiating effect on insulin secretion is restricted to GSH since under identical conditions GSSG was found even to be inhibitory [7].

As shown in Table 1 in the non-fasted state the concentration of arterial plasma GSH was only slightly less $(6.5 \mu \mathrm{mol} / \mathrm{l})$ than the concentration of exogenous $\mathrm{GSH}$ which produces the half-maximal synergistic effect on insulin release in vitro (approximately $10 \mu \mathrm{mol} / \mathrm{l}$ ). These observations suggest that physiological alterations of the plasma concentration of GSH might affect the sensitivity of the B cell to respond to glucose in vivo as previously suggested when the role of intracellular GHS in insulin release was studied in vitro [18]. Such a view, however, would predict that plasma GSH is not static but varies under conditions of food intake. In fact, when glucose was given orally in rats an increase of arterial plasma GSH could be observed.

As far as the insulinotropic effect of extracellular GSH is concerned it appears to be localized at the external site of the plasma membrane since we could not demonstrate the uptake of labelled GSH into pancreatic islet cells confirming similar data with respect to the liver [18].

So far the mechanism of action of extracellular GSH on the discharge of insulin remains to be evaluated. Previous evidence suggests, that it is at least different from the action of intracellular GSH: Whereas intracellular GSH appears to be related to $\mathrm{Ca}^{2+}$ uptake via the voltage dependent $\mathrm{Ca}^{2+}$ channel, there was no evidence for such an action of extracellular GSH [12, 19].

The source for the elevation of plasma GSH in response to glucose is not yet known. Considerable amounts of plasma GSH are derived from the liver [8, 20]. However, from our experiments with the isolated perfused liver there is no evidence for a direct stimulatory action of glucose and insulin on GSH release. This does not exlude the possibility that in vivo glucose may increase plasma GSH indirectly. Interestingly, epinephrine and vasopressin were previously found to stimulate GSH release from liver [21]. However, changes of GSH metabolism by the kidney and release from other tissues may be taken into consideration [22].

In conclusion, our data show that plasma GSH is increased by the elevation of plasma glucose. This, and the observation that in a similar concentration range exogenous GSH potentiates glucose-mediated secretion of insulin in vitro and/or in vivo suggest a possible direct physiological function of plasma GSH in glucose-mediated insulin secretion.

\section{References}

1. Ammon HPT, Akhtar MS, Niklas H, Hegner D (1977) Inhibition of p-chloromercuribenzoate- and glucose-induced insulin release in vitro by methylene blue, diamide and tert-butyl hydroperoxide. Mol Pharmacol 13: 598-605

2. Ammon HPT, Hoppe E, Akhtar MS, Niklas H (1979) Effect of leucine on the pyridine nucleotide contents of islets and on the in- sulin released: interactions in vitro with methylene blue, thiol oxidants and p-chloromercuribenzoate. Diabetes 28: 593-599

3. Ammon HPT, Akhtar MS, Grimm A, Niklas H (1979) Effect of methylene blue and thiol oxidants on pancreatic islet GSH/GSSG ratios and tolbutamide mediated insulin release in vitro. Naunyn Schmiedeberg's Arch Pharmacol 307:91-96

4. Ammon HPT, Grimm A, Lutz S, Wagner-Teschner D, Händel M, Hagenloh I (1980) Islet glutathione and insulin release. Diabetes 29: $830-834$

5. Anjaneyulu K, Anjaneyulu R, Sener A, Malaisse WJ (1982) The stimulus-secretion coupling of glucose-induced insulin release. Thiol:disulfide balance in pancreatic islets. Biochimie 64: 29-36

6. Hellman B, Idahl LA, Lernmark $\AA$, Sehlin J, Täljedal IB (1975) Stimulation of insulin release by thiols. Biochim Biophys Acta 392: 101-109

7. Ammon HPT, Hehl KH, Enz G, Setiadi-Ranti A, Verspohl EJ (1986) Cysteine analogues potentiate glucose-induced insulin release in vitro. Diabetes 35: 1390-1396

8. Anderson ME, Bridges RJ, Meister A (1980) Direct evidence for inter organ transport of glutathione and that the nonfiltration renal mechanism for glutathione utilization involves gamma-glutamyltranspeptidase. Biochem Biophys Res Commun 96: 848-853

9. Meister A, Anderson ME (1983) Glutathione. Ann Rev Biochem 52: $711-760$

10. Lacy PE, Kostianovsky M (1967) Method for isolation of intact islets of Langerhans from the rat pancreas. Diabetes 16: 35-39

11. Ammon HPT, Abdel-Hamid M, Rao PG, Enz G (1984) Thiol-dependent and non-thiol-dependent stimulations of insulin release. Diabetes 33: 251-257

12. Ammon HPT, Hägele R, Youssif N, Eujen R, El-Amri N (1983) A possible role of intracellular and membrane thiols of rat pancreatic islets in calcium uptake and insulin release. Endocrinology 112: $720-725$

13. Jaeschke H, Krell H, Pfaff $E$ (1983) No increase of biliary permeability in ethinylestradiol-treated rats. Gastroenterology 85 : 808-814

14. Krell H, Jaeschke H, Hölke H, Pfaff E (1983) Bile secretion in hemoglobin-free perfused rat liver. Hoppe-Seyler's $Z$ Physiol Chem 365: 1115-1122

15. Brehe JE, Burch HB (1976) Enzymatic assay for glutathione. Anal Biochem 74: 189-197

16. Heinle $H$ (1979) The degree of glutathione oxidation in excised aortic tissue of rats and rabbits. Hoppe Seyler's Z Physiol Chem 360: 1113-1116

17. Soeldner JS, Slone D (1965) Critical variables in the radioimmunoassay of serum insulin using the double antibody technique. Diabetes 14: 771-779

18. Hahn R, Wendel A, Flohe L (1978) The fate of extracellular glutathione in the rat. Biochim Biophys Acta 539:324-337

19. Ammon HPT, Mark M (1985) Thiols and pancreatic $\beta$-cell function: a review. Cell Biochem Funct 3: 157-171

20. Ookhtens M, Hobdy K, Corvasce MC, Aw TY, Kaplowitz N (1985) Sinusoidal efflux of glutathione in the perfused rat liver. Evidence for a carrier-mediated process. J Clin Invest 75:258-265

21. Sies H, Graf P (1985) Hepatic thiol and glutathione efflux under the influence of vasopressin, phenylephrine and adrenaline. Biochem J 226: 545-549

22. Hill KE; Burk R (1985) Effect of selenium deficiency on the disposition of plasma glutathione. Arch Biochem Biophys 240: 166-171

Received: 12 December 1988

and in final revised form: 30 August 1989

Dr. H.P.T.Ammon

Department of Pharmacology

Institute of Pharmaceutical Sciences

Auf der Morgenstelle B

D-7400 Tübingen

FRG 